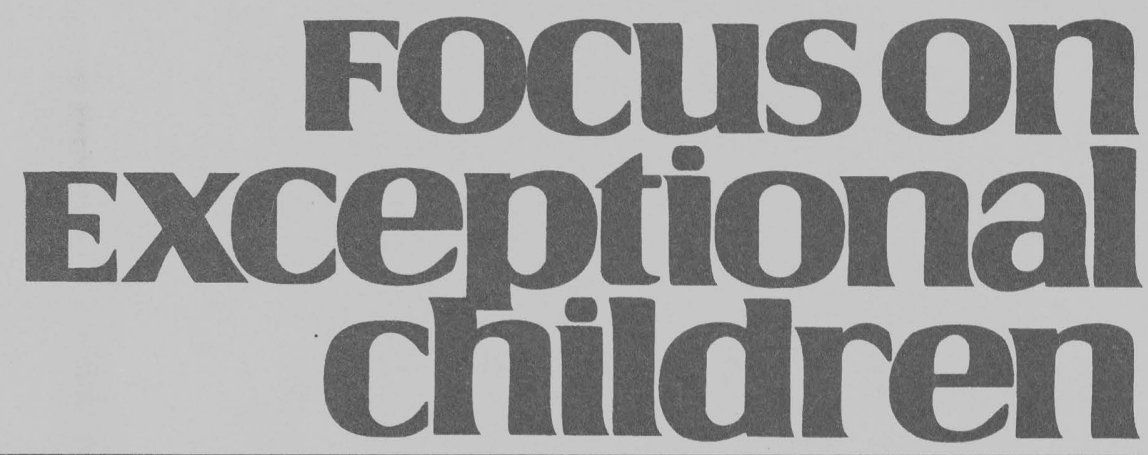

\title{
Identifying Appropriate Test Accommodations for Students With Learning Disabilities
}

\author{
Lynn S. Fuchs, Douglas Fuchs, and Andrea M. Capizzi
}

Accountability is a prominent issue in public education. A great deal of time, money, and student and teacher effort is spent on testing students' academic achievement and progress to evaluate the educational outcomes of schools, school systems, and states. Students enrolled in public schools sometimes take eight or more sets of standardized tests throughout their school career. The No Child Left Behind Act of 2001 (NCLB) requires that all students enrolled in public schools take a reading and math assessment each year in grades 3 through 8 , and to be tested at least once during grades 10 through 12 . By the 2007-08 school year, the NCLB also will require testing in science at least once during grades 3 through 5, 6 through 9, and 10 through 12. As of June 10, 2003, all 50 states, the District of Columbia, and Puerto Rico had federally approved statewide accountability plans in accordance with the NCLB (Webb \& Aspey, 2003).

Despite broad implementation of assessment plans, testing varies widely within states, in terms of the amount and type of accountability. Often, outcomes measured by high-stakes assessments are tied to funding, which makes the results important to local and state school administrators. The NCLB holds states and schools accountable for their effectiveness and continuous improvement. Schools that fail to meet performance objectives can lose federal funds, and Title 1 funds can be diverted to allow students in failing schools to transfer to higher-performing schools. NCLB also has provisions for rewarding bonuses to successful schools.

Because of the nature of their academic difficulties, students with disabilities often present particular challenges for administrators and educators when standardized high-stakes assessments are concerned. In the past, states have not always included students with disabilities in their assessment systems and analyses. Low participation rates of students with disabilities continued despite mandates for their being included in accountability programs required by 1997 amendments to the Individuals with Disabilities Education Act (IDEA) (Fuchs \& Fuchs, 2001). In essence, the scores of these students and their outcomes did not count (Fuchs \& Fuchs, 1999; Fuchs, Fuchs, Eaton, Hamlett, \& Karns, 2000).

In an effort to gain full information regarding the educational outcomes for all students, the NCLB requires that students with disabilities be included in tests to the fullest extent possible. This further commitment to gaining information about outcomes for students with disabilities recognizes the importance of this population of students and requires

Dr. Lynn Fuchs and Dr. Doug Fuchs are with the special education faculty of Peabody College of Vanderbilt University. Andrea M. Capizzi is a doctoral student with Peabody College of Vanderbilt University. Inquiries should be directed to Lynn Fuchs, 328 Peabody, Vanderbilt University, Nashville, TN 37203. 
states to include them in their assessments. Acknowledging this population of students by including them in assessment programs is essential to generate summative information that can be used to formulate challenging educational goals and improve programs for these students within the context of federal, state, and local education agencies (Fuchs \& Fuchs, 2001).

Mandates to include students with disabilities should increase their participation in educational outcome assessments. Yet, because of the very nature of their disabilities, these students often are unable to participate in assessments in the same fashion as their nondisabled peers. For many students, accommodations are necessary to provide a true measure of a student's knowledge. Further, the Americans with Disabilities Act of 1990 (ADA) has incited debate about whether accommodations should be provided to individuals with a wide variety of disabilities including learning disabilities and dyslexia (Phillips, 1994). As of 1997, 40 states had active policies on testing accommodations and eight states were in the process of revising or developing such policies (Thurlow, House, Scott, \& Ysseldyke, 2000). As more students with disabilities are included in high-stakes

\section{Focuson
Exceptional
children}

ISSN $0015-511 \mathrm{X}$ FOCUS ON EXCEPTIONAL CHILDREN (USPS 203-360) is published monthly except June, July, and August as a service to teachers, special educators, curriculum specialists, administrators, and those concerned with the special education of exceptional children. This publication is annotated and indexed by the ERIC Clearinghouse on Handicapped and Gifted Children for publication in the monthly Current Index to Journals in Education (CIJE) and the quarterly index, Exceptional Children Education Resources (ECER). The full text of Focus on Exceptional Children is also available in the electronic versions of the Education Index. It is also available in microfilm from Xerox University Microfilms, Ann Arbor, MI. Subscription rates: individual, \$36 per year; institutions, \$48 per year. Copyright (C) 2005, Love Publishing Company. All rights reserved. Reproduction in whole or part without written permission is prohibited. Printed in the United States of America. Periodical postage is paid at Denver, Colorado. POSTMASTER: Send address changes to:

Love Publishing Company

Executive and Editorial Office P.O. Box 22353

Denver, Colorado 80222

Telephone (303) 221-7333

\section{EDITORIAL BOARD}

Edwin Ellis

University of Alabama
Tim Lewis

University of Missouri

Chriss Walther-Thomas

University of Kansas

Susan T. Warhover Editor
Stanley F. Love Publisher testing, information on the provision of valid accommodations will be essential to educators and administrators.

In this article we provide an overview of identification of appropriate testing accommodations for students with learning disabilities (LD). First we define the concept of testing accommodations and review research on test accommodations commonly used with students with LD. Next we examine the validity and fairness in accommodations, as well as the role of the Individualized Education Program (IEP) team in testing accommodation decision making. The issue of heterogeneity in LD and individualization of accommodations is discussed with particular focus on issues related to identification of appropriate accommodations, along with a description of an objective and empirically sound system for identifying accommodations. Finally, we consider implications for research on accommodations, as well as practical selection and use of accommodations in educational outcomes assessment.

\section{WHAT IS A TEST ACCOMMODATION?}

Given the push to include more students with disabilities in outcomes assessments, it follows that more students need accommodations to take these tests. Testing accommodations are changes in the way tests are given that differ from the conditions under which the tests were standardized. The point of providing accommodations is to "level the playing field" for students with disabilities by allowing them to demonstrate what they are able to do without their competence being obscured by their disabilities (Fuchs \& Fuchs, 1999; Tindal \& Fuchs, 2000). Common accommodations include modification of test presentation, methods of responding, test setting, and timing or scheduling of tests (Ysseldyke, Thurlow, McGrew, \& Shriner, 1994). Table 1 provides a list of common accommodations.

\section{What We Know About the Effects of Test Accommodations on Students With LD}

Despite some empirical work, research does not provide the field with a "package" of accommodations that is useful to all students with LD. Certain accommodations benefit some students with LD, but no single accommodation has been shown to benefit all students with LD. Actually, empirical evidence demonstrates that, compared to their typical peers, many students with disabilities do not profit differentially from typical accommodations, such as timing of the test and writing answers directly on the test (Fuchs \& Fuchs, 1999; Fuchs, Fuchs, Eaton, Hamlett, Binkley, \& Crouch, 2000; Fuchs, Fuchs, Eaton, Hamlett, \& Karns, 2000; Tindal \& Fuchs, 2000; Tindal, Heath, Hollenbeck, Almond, \& Harniss, 1998). Another common accommodation - orally reading the test to students-has been shown to be helpful to 


\section{TABLE 1 Commonly Awarded Testing Accommodations}

Setting

Alternative testing location

Individual or small-group administration

Study carrel or other method to minimize distractions

\section{Timing of Test}

Extended time to complete test

Testing without time constraints

Administration over several days

Breaks during testing

\section{Test Format (Presentation or Responding)}

Braille or large print

Test read aloud to student

Directions/wording simplified for, or read to, student

Student marks answers in booklet rather than on answer sheet

Answers dictated or signed to a scribe by student

Test student on different-level test

\section{Technological Supports}

Assistive communication device

Window cards to reduce visible print

Magnification devices

Word processor

Calculator or math-fact tables

Brailler

Dictionary or speller

Adaptive pencils or other writing aids

Compiled from: Testing Students with Disabilities: Practical Strategies for Complying with District and State Requirements, by M. L. Thurlow, J. L. Elliott, and J. E.Ysseldyke (Thousand Oaks, CA: Corwin Press, 2003); and A Summary of Research on Test Changes: An Empirical Basis for Defining Accommodations, by G. Tindal and L. S. Fuchs (Lexington, KY: Mid-South Regional Resource Center, Interdisciplinary Human Development Institute, 2000).

some students and detrimental to others (Helwig \& Tindal, 2003; Tindal et al., 1998).

Although several test accommodations have been evaluated in isolation, practitioners often implement several accommodations at the same time to provide more comprehensive accommodation plans for students. Elliott, Kratochwill, and McKevitt (2001) have criticized past empirical efforts evaluating the effectiveness of specific testing accommodations. Those authors stressed the importance of studying packages of accommodations rather than single accommodations in isolation because accommodations tend to be used in packages in practice.
This seems like a relevant idea and point but also seems premature given the limited research base on test accommodations. Until specific accommodations are determined to be useful for large numbers of students within a disability group, evaluating accommodation packages is inefficient. Without identifying effective singular accommodations, empirically effective packages may include extraneous accommodations that do not contribute to the effectiveness of the package. A more straightforward method may be to identify specific accommodations that are effective for some students. Once identified, combinations of these potentially effective accommodations and increased benefits could be evaluated.

Providing testing accommodations during outcome measurement can be costly, and administering tests to students becomes more difficult as the number of accommodations increases. Ineffective accommodations waste funds, as well as student and staff energy. For this reason, we provide a brief overview of research on four common specific accommodations: offering extended time, having the student write on the test rather than bubble-in the answers on a separate sheet, orally reading the test to the student, and providing an alternative testing setting. (For a thorough summary of research on many specific accommodations, we refer the reader to Tindal and Fuchs, 2000.)

\section{Extended Time}

Providing extra time for students to complete tests can result in higher scores. General and special education students alike can benefit from extended time. Interestingly, typically-achieving students have demonstrated more benefit than students with LD from extended time accommodations (Fuchs, Fuchs, Eaton, Hamlett, Binkley, et al., 2000). Research on extended time accommodations has demonstrated increased scores for general and special education students alike, with no differential boost for students with disabilities (Fuchs, Fuchs, Eaton, Hamlett, Binkley, et al., 2000; Fuchs, Fuchs, Eaton, Hamlett, \& Karns, 2000; Tindal \& Fuchs, 2000).

Interestingly, students with LD whose primary difficulties were in reading and whose IEP did not include math goals had larger boosts in performance from extended time on math tests than did students with LD who had noted math difficulties (Fuchs, Fuchs, Eaton, Hamlett, \& Karns, 2000). Therefore, available work raises questions about the validity of extra time accommodations and certainly does not demonstrably benefit all students with LD. This is unfortunate because extended time is the most frequently awarded accommodation for students with LD (Fuchs \& Fuchs, 2001).

If the goal of testing is to obtain a fair score, which is representative of what a student knows, care should be taken in providing this accommodation. The one exception may be for students with LD who have reading difficulties but are 
proficient in mathematics. Extended time may allow these students sufficient time to read tests and better demonstrate math skills that would be overshadowed by their reading disabilities.

\section{Writing Directly on the Test}

Another common accommodation is to allow a student to write directly on a test rather than bubble-in on a separate answer sheet. The thought behind this accommodation is that allowing students to write directly on the test will free them from the effort of bubbling-in so they can apply themselves entirely to answering the questions, and also will eliminate errors associated with faulty transcription of the correct answers.

No empirical study has found this accommodation to be effective in producing gains in scores for students with LD. Several studies have demonstrated no significant effects as a result of allowing general and special education students to write on the test (Mick, 1989; Tindal et al., 1998; Veit \& Scruggs, 1986). This accommodation, although inexpensive and used frequently, may not truly benefit students with disabilities. At the present time, research does not support its use with students with LD.

\section{Oral Presentation of Test}

Effects of reading tests to students have been mixed. Tindal et al. (1998) found that students in special education performed better on math tests when the items were presented orally. Fuchs, Fuchs, Eaton, Hamlett, and Karns (2000) found that presenting a test orally produced more score gains for students with LD over their nondisabled peers, demonstrating the validity of this accommodation. Helwig and Tindal (2003) were unable to develop a profile of students who preferred having mathematics tests read aloud to them and those who preferred traditional presentation of tests. This demonstrates that the response to certain accommodation preferences may be individual rather than tied to disability categories.

Presenting text orally may be a valid accommodation for students with LD, but this accommodation should be used with care. Although it may be valid and not interfere with standard presentation for math tests, oral presentation may be unfair and overestimate the scores of students when applied to reading tests.

\section{Alternative Setting}

Testing students with LD in alternative environments is a common accommodation. Students often are tested in resource settings with fewer students. The intent is to provide students with a testing environment with fewer distractions. Unfortunately, at this time, no empirical studies have been done to measure the effect of setting accommodations on the scores of students with LD. If tests are delivered according to standard conditions within an alternative school setting, this should not lead to inflated students' scores and actually may allow students to focus their attention and produce a truer representation of their ability.

In practice, accommodations in setting rarely are delivered without being paired with other accommodations. Alternative testing environments allow resource teachers to provide their students with LD other accommodations such as extended time or oral presentation of the test. Until studies are conducted on the validity of setting accommodations, it may be prudent to consider the setting accommodation, on its own, to be a valid accommodation, but to take care when considering it in combination with other accommodations that lead to nonstandard test administration.

\section{WHAT IS A FAIR ACCOMMODATION?}

For students of certain disability groups, the decision to provide fair accommodations is straightforward, and for other groups it is more ambiguous. On the one hand, providing a test in large print or Braille to a student with a visual impairment does not give rise to a question of fairness. On the other hand, the cognitive difficulties of students with impairments such as LD are often at the core of the skills being assessed by outcome measures (Fuchs \& Fuchs, 2001). Furthermore, the heterogeneity among students with LD increases the difficulty of identifying a set of accommodations that are suited specifically to the whole group (Fuchs, Fuchs, Eaton, Hamlett, Binkley, et al., 2000).

The desire to preserve meaningfulness of scores is central to the issue of fairness in accommodations. Nonstandard administration of standardized tests can threaten the validity of test scores obtained under this administration. An option may be to ease standardization requirements to allow for the accommodations that students with disabilities need. This would build in needed accommodations while ensuring that the test continues to measure the intended construct (Pitoniak \& Royer, 2001).

Valid accommodations help students with disabilities demonstrate their knowledge and produce scores that evaluate the same constructs that are intended with standardized measurement of nondisabled peers (Fuchs \& Fuchs, 2001; McDonnel, McLaughlin, \& Morison, 1997; Phillips, 1994). To withhold accommodations that allow students with disabilities to demonstrate knowledge and skills that are obscured by their disabilities would be unfair-as would accommodations that lead to scores that overestimate a student's ability. Accommodations that inflate scores are unfair because they are not representative of a student's or a group of students' outcomes.

Misrepresentation of a group of students could contribute to a "domino effect," wherein policy decisions, expectations, and, ultimately, student outcomes are tied incorrectly to inflated results. Given the federal commitment to producing 
positive educational outcomes for students, inflated results may reduce pressures on education agencies to produce results for students with disabilities.

The validity of an accommodation can be evaluated by considering whether it speaks to the nature of the disability itself (Fuchs, Fuchs, Eaton, Hamlett, Binkley, et al., 2000). A valid accommodation should help a student compensate for his or her disability by increasing the student's access that will allow him or her to demonstrate his or her knowledge. Accommodations should allow students to earn valid, not necessarily optimal, scores (Fuchs, Fuchs, Eaton, Hamlett, Binkley, et al., 2000). The validity of an accommodation can be evaluated by determining whether it produces a differential boost (Fuchs, Fuchs, Eaton, Hamlett, Binkley, et al., 2000; Fuchs, Fuchs, Eaton, Hamlett, \& Karns, 2000; Phillips, 1994). A differential boost is demonstrated when an accommodation produces a greater gain in score for a student with a disability than a nondisabled student with the same accommodation would gain (Phillips, 1994).

For example, providing a large-print test to a student with a visual impairment may allow access to the test for that student and lead to a higher score over what the student would have produced on a standard version of the test. Such an accommodation probably would not increase the score of a nondisabled student in the same manner.

This accommodation speaks to the nature of the student's disability and, therefore, is valid. But if an accommodation, such as extended time to complete a test, increases the score of a student with a disability similar to increases for nondisabled students, the accommodation would not be considered valid because the accommodation has nothing inherent to compensate for the disability. The accommodation is equally helpful to students with and without disabilities and, therefore, is not uniquely characteristic of the disability. Attention to the nature and characteristics of disabilities that impact assessment of students with disabilities is essential to identify fair and valid testing accommodations.

\section{WHO MAKES ACCOMMODATION DECISIONS?}

As mandated by IDEA, testing and instructional accommodations must be considered during planning and development of the Individual Education Plan (IEP). Generally, members of the IEP team make accommodation decisions to maintain compliance with IDEA, which requires modifications and accommodations for state and district educational outcomes assessments to be included in IEPs (Thurlow, Elliott, \& Ysseldyke, 2003). Assessment accommodations are not always equivalent to instructional modifications and must be considered specifically for use during testing (Thurlow et al., 2000).

Most IEP teams include, at the very least, the student's parent, special education teacher, school administrator, and general education teacher. Teams also may include other service providers, and the student when appropriate. The testing accommodation decisions of IEP teams are of great importance. In examining state policies on testing accommodations, Thurlow et al. (2000) found that nearly all states with active accommodation policies deferred to the decisions of IEP teams when determining student participation in testing.

Ideally, including a diverse group of IEP team members encourages consideration of various aspects of the student that contribute to his or her educational needs. Parents, administrators, and teachers bring varying viewpoints and pressures to the process of planning IEPs and can offer support and suggestions in developing IEPs. Teachers-because they have the greatest amount of educational engagement with students - take a primary role in identifying appropriate accommodations. This is disconcerting, given past research that shows teachers to be ineffective at choosing accommodations that benefit students (Fuchs, Fuchs, Eaton, Hamlett, Binkley, et al., 2000; Fuchs, Fuchs, Eaton, Hamlett, \& Karns, 2000; Helwig \& Tindal, 2003).

Helwig and Tindal (2003) found that teachers were no more successful than chance at identifying students who would benefit from read-aloud testing accommodations. Their results uphold prior findings in math and reading showing that teachers' choices of accommodations for students did not correspond with those from which students actually profit (Fuchs, Fuchs, Eaton, Hamlett, Binkley, et al., 2000; Fuchs, Fuchs, Eaton, Hamlett, \& Karns, 2000).

Furthermore, student demographic characteristics may influence teachers' awarding of accommodations (Fuchs \& Fuchs, 2001). Past studies have shown that a disproportionate number of accommodations are awarded to students who are African American, receive free or reduced-price lunches, or have lower IQs or reading levels (Fuchs, Fuchs, Eaton, Hamlett, Binkley, et al., 2000). Given these research findings, caution should be taken when relying on subjective teacher judgments about test accommodations (Fuchs \& Fuchs, 1999).

\section{HETEROGENEITY IN LD AND INDIVIDUALIZATION OF ACCOMMODATIONS}

Students with LD make up approximately $6 \%$ of the total population of students enrolled in public $\mathrm{K}-12$ schools (Office of Special Education Programs, 2002; National Center for Educational Statistics, 2001). This is the largest category of disability. Students with LD comprise a diverse population, with varied profiles of skill deficits and strengths. This group of students has a large range of cognitive and academic difficulties. A strength for one student with LD may be a struggle for another.

The heterogeneity in the LD population, along with the limited research base on test accommodations, creates 
difficulty in identifying valid accommodations (Fuchs \& Fuchs, 2001). Past studies have demonstrated the difficulty in developing student profiles that fit certain accommodations (Helwig \& Tindal, 2003). Furthermore, some accommodations actually harm students and worsen their scores (Schulte, Elliott, \& Kratochwill, 2001). Individual decision making on valid testing accommodations, akin to individualization recommended for IEPs, seems necessary to identify specific accommodations from which each student with LD will benefit.

\section{DATA: AN OBJECTIVE MEANS OF IDENTIFYING VALID ACCOMMODATIONS}

Past research has demonstrated that identifying valid accommodations for students with disabilities is not a simple, straightforward task. Clearly, consideration of accommodations is mandated. Moreover, accommodations benefit some students. How best to identify accommodations, however, is unclear. If (a) teachers, the primary source of accommodation decisions, are ineffective at identifying valid accommodations, and (b) many common accommodations are ineffective with certain students, how should accommodations be identified? An empirically sound, objective method to help teachers identify accommodations (i.e., a method that preserves the meaningfulness of test scores while allowing students to demonstrate their full abilities) is needed. The Dynamic Assessment of Test Accommodations (DATA) provides such a tool.

DATA is a brief assessment process to aid teachers in identifying accommodations that offer a differential boost for individual students (Fuchs \& Fuchs, 2001). It was developed in response to teachers' confusion over what testing accommodations might be valid and appropriate for individual students (Fuchs \& Fuchs, 2001). DATA is a useful tool because it is brief, individualized, and helps teachers identify specific accommodations that are valid for each student.

In using DATA, teachers administer brief tests, with and without accommodations, to students with LD. Following testing, teachers evaluate the boost in performance gained for each student with the accommodation. The boost for each student then is compared to normative information on the effects of these accommodations on nondisabled students (accommodated score minus standard format score). If an accommodation exceeds a boost that would be expected for nondisabled students, it is considered a valid accommodation for that student (Fuchs \& Fuchs, 2001). DATA is available for use with students with LD in grades $2-7$ in reading and math.

Empirical study of DATA has yielded promising results. It has been used to guide teachers' test accommodation decisions in reading and mathematics (Fuchs, Fuchs, Eaton,
Hamlett, Binkley, et al., 2000; Fuchs, Fuchs, Eaton, Hamlett, $\&$ Karns, 2000). A version of DATA was developed to aid in identifying math test accommodations that produce a differential boost for individual students with LD. With DATAMath, curriculum-based measurement uses alternative forms of math problems (computations, concepts and applications, and problem solving) and presents varying types of accommodations (standard, extended time, calculators, and an adult reading text aloud). Each type of problem is presented to students in standard format and with accommodations.

For example, in addition to standard format, computation problems are presented with extended time and with an adult reading text aloud. The concepts and applications problems are presented in standard format, with extended time, and with calculators. Problem-solving items are presented in standard format, with extended time, with calculators, and with an adult reading text. Students' scores during standard administration are compared with each accommodation to determine whether the accommodation was accompanied by a differential boost.

In DATA-Math, a student receives a problem-solving, curriculum-based measurement under standard conditions, wherein the student reads the problems to himself or herself. Next the student receives a comparable problem-solving, curriculum-based measurement with the accommodation of having text read aloud to him or her. Both curriculum-based measurements are scored, and the boost of the accommodation (accommodated test score minus standard test score) is compared to that of typical peers. If the student's boost well exceeds the boost obtained by typical peers, the accommodation is considered to help the student compensate for his or her disability and therefore is deemed valid. Evaluation of DATA-Math showed that it provided valuable supplemental information that enhanced teachers' decision making, and helping them to identify fair and valid accommodations (Fuchs, Fuchs, Eaton, Hamlett, \& Karns, 2000).

A form of DATA also has been developed and evaluated for use with reading tests (Fuchs, Fuchs, Eaton, Hamlett, Binkley, et al., 2000). Curriculum-based measurements used in DATA-Reading include printed passages followed by multiple-choice comprehension questions. In DATA-Reading, students are administered brief reading curriculumbased measurements under standard (student reading silently) and accommodated conditions (extended time, large print, and student reading aloud). For each accommodation, the student's curriculum-based measurement score with the accommodation is compared to his or her score with standard administration. As with DATA-Math, the student's boost is compared to scores obtained by nondisabled grade-level peers. If a student's boost exceeds that expected for nondisabled peers, the accommodation is considered acceptable. 
For example, if a student with $\mathrm{LD}$ receives a reading curriculum-based measurement with a large-print accommodation and the boost he or she earns is comparable to that of grade-level nondisabled peers, large-print would not be considered a valid accommodation. If, however, the student reads the test aloud (to himself or herself) during testing and earns a score that sufficiently exceeds his or her score with the standard administration (silent reading) beyond what typically is demonstrated by nondisabled peers, this read-aloud accommodation is deemed appropriate. Furthermore, this accommodation should be provided for this student during future classroom testing and district and state assessments.

Both DATA-Math and DATA-Reading have been used successfully to identify valid accommodations for application during standardized testing (Fuchs, Fuchs, Eaton, Hamlett, Binkley, et al., 2000; Fuchs, Fuchs, Eaton, Hamlett, \& Karns, 2000). The brief time invested in using an objective means to identify appropriate accommodations, such as DATA, helps teachers identify accommodations that are both valid and effective. In the long run, the time invested in using a measure such as DATA can help educators maximize their resources without providing time-consuming, yet ineffective, accommodations. Probably more important, objective means of making accommodation decisions can ensure that educators are providing students with accommodations that help them earn scores more representative of their skills.

\section{A Summary of What We Know}

Compliance with federal mandates (ADA, IDEA, NCLB) requires the inclusion of students with disabilities in educational outcome measurement. It also requires consideration of testing accommodations. The need for research-based practices to guide testing accommodation decisions for students with $\mathrm{LD}$ is paramount. Despite a meager research-base on testing accommodations, the following generalizations seem sound.

1. The same accommodation is not effective or valid for all students. An accommodation that benefits some students may not benefit, or may even hinder, other students with the same disability. For this reason, decisions about accommodations have to be individualized, especially considering the heterogeneity of skills and deficits that students with LD demonstrate.

2. Of primary importance, the meaningfulness of scores must be retained when selecting and implementing accommodations.

3. Research on testing accommodations is both relevant and essential because of the mandated consideration of educational outcome testing for students with disabilities.
As the number of students included in high-stakes testing increases, so does the need for research to guide test-accommodation decisions. Clearly, further study of various types of accommodations is warranted, but any one accommodation is unlikely to be a panacea for all related testing issues of students with LD. If specific accommodations are found to benefit most students with LD, then and only then should we begin thinking about packages of accommodations as recommended by Elliott et al. (2001). Exerting experimental control in research over each accommodation is essential to identify valid accommodations.

Maintaining meaningfulness of scores during accommodated testing also should be a primary goal of future research and practice. As Phillips (1994) noted, the impact of accommodations with nondisabled populations should be considered when choosing and evaluating test accommodations. Examination of accommodated score boosts for students with disabilities, as compared to those of their nondisabled peers, offers a meaningful way to identify valid accommodations with less likelihood of overestimating the skill and performance of a student with LD.

\section{PRACTICAL-THOUGH PREMATURE- IMPLICATIONS}

It would be a luxury to continue conducting research on testing accommodations, to arrive at empirically validated conclusions, and to identify a set of practices that could be recommended to teachers and administrators for use with their students prior to implementation of any high-stakes testing with students with LD. Unfortunately, including students with disabilities in state assessments is under way even as conclusions about selecting and implementing testing accommodations remain unclear. Still, some practical implications can guide decisions about accommodations.

Although teachers often take a primary role in formulating test-accommodation decisions, those decisions are often subjective and ineffective. Teachers have to be supported in their decision making and provided objective means for identifying valid and appropriate accommodations for individual students. An assessment system such as DATA offers one option for guiding teacher decisions. Teachers will remain an integral part of accommodation decision making because of their familiarity with individual students in the educational setting.

Providing teachers with tools to help them identify appropriate accommodations and to help teachers better understand the meaningfulness of tests and the validity of scores may enhance their ability to select test accommodations for their students. Enlisting the support and knowledge of school staff members who have knowledge of the psychometric properties and aims of the tests being utilized also may support valid accommodation decisions. 
Even with the concerns about teachers as decision makers, researchers have documented two promising accommodations that may be useful in educational outcomes testing (Fuchs \& Fuchs, 2001):

1. When students with LD have severe reading deficits, encourage them to read the test aloud to themselves.

2. Have an adult read the text on math tests to students with severe reading difficulties.

\section{CONCLUSION}

Measurement of educational outcomes via standardized assessment procedures has been, and will most likely continue to be, a prevalent practice in public education. Given the continued push for evaluation in math and reading and the upcoming expansion to science, the skills of students with LD must be represented adequately in the public database. The NCLB and National Assessment of Educational Progress (NAEP) stress the need to include in the testing students with disabilities from all areas and skill levels. The data obtained from state and national assessments can bring to light deficiencies in programs for students-general and special education alike.

As more students take these tests, the scores must represent skill levels accurately. Accommodations can either help or hinder this aim. Accommodations that lead to inflated and invalid scores are especially dangerous. Overestimating a group's performance potentially leads to underfunding or maintaining ineffective programs. This is particularly damaging to students at risk of or already struggling in school.

If time is to be invested in testing the progress and educational outcomes of students with disabilities, that time also should be invested in identifying accommodations that ensure testing validity. Educators should take great care in using accommodations that are valid and fair. Objective methods of identifying test accommodations, such as DATA, help teachers invest the same care in choosing accommodations as they do in other aspects of their students' educational programs.

\section{REFERENCES}

Elliott, S. N., Kratochwill, T. R., \& McKevitt, B. C. (2001). Experimental analysis of the effects of testing accommodations on the scores of students with and without disabilities. Journal of School Psychology, 39, $3-24$.

Fuchs, L. S., \& Fuchs, D. (1999). Fair and unfair testing accommodations. School Administrator, 24-29.

Fuchs, L. S., \& Fuchs, D. (2001). Helping teachers formulate sound test accommodation decisions for students with learning disabilities. Learning Disabilities Research and Practice, 16, 174-181.

Fuchs, L. S., Fuchs, D., Eaton, S. B., Hamlett, C. L., Binkley, E., \& Crouch, R. (2000). Using objective data sources to enhance teacher judgments about test accommodations. Exceptional Children, 67, 67-81.
Fuchs, L. S., Fuchs, D., Eaton, S. B., Hamlett, C. L., \& Karns, K. (2000). Supplementing teacher judgments of mathematics test accommodations with objective data sources. School Psychology Review, 29, $65-85$.

Helwig, R., \& Tindal, G. (2003). An experimental analysis of accommodation decisions on large-scale mathematics tests. Exceptional Children, 69, 211-225.

McDonnel, L. M., McLaughlin, M. J., \& Morison, P. (Eds.). (1997). Educating one and all: Students with disabilities and standards-based reform. Washington, DC: National Academy Press.

Mick, L. (1989). Measurement effects of modifications in minimum competency test formats for exceptional students. Measurement and Evaluation in Counseling and Development, 22, 31-36.

National Center for Educational Statistics. (2001). Public School Student, Staff, and Graduate Counts by State: 2000-2001. Washington, DC: Author.

Office of Special Education Programs. (2002). 24th Annual Report to Congress on the Implementation of the IDEA. Washington, DC: Author.

Phillips, S. E. (1994). High-stakes testing accommodations: Validity versus disabled rights. Applied Measurement in Education, 7, 93-120.

Pitoniak, M. J., \& Royer, J. M. (2001). Testing accommodations for examinees with disabilities: A review of psychometric, legal, and social policy issues. Review of Educational Research, 71, 53-104.

Schulte, A. G., Elliott, S. N., \& Kratochwill, T. R. (2001). Effects of testing accommodations on standardized mathematics test scores: An experimental analysis of the performances of students with and without disabilities. School Psychology Review, 30, 527-547.

Thurlow, M. L., Elliott, J. L., \& Ysseldyke, J. E. (2003). Testing students with disabilities: Practical strategies for complying with district and state requirements. Thousand Oaks, CA: Corwin Press.

Thurlow, M. L., House, A. L., Scott, D. L., \& Ysseldyke, J. E. (2000). Students with disabilities in large-scale assessments: State participation and accommodation policies. Journal of Special Education, 34, 154-163.

Tindal, G., \& Fuchs, L. S. (2000). A summary of research on test changes: An empirical basis for defining accommodations. Lexington, KY: MidSouth Regional Resource Center Interdisciplinary Human Development Institute.

Tindal, G., Heath, B., Hollenbeck, K., Almond, P., \& Harniss, M. (1998). Accommodating students with disabilities on large-scale tests: An experimental study. Exceptional Children, 64, 439-450.

Veit, D. T., \& Scruggs, T. E. (1986). Can learning disabled students effectively use separate answer sheets? Perceptual and Motor Skills, 63, $155-160$.

Webb, J., \& Aspey, S. (2003, June 10). President Bush, Secretary Paige celebrate approval of every state accountability plan under No Child Left Behind. Retrieved January 6, 2004, from http://www.ed.gov/news/ pressreleases/2003/06/06102003.html

Ysseldyke, J. M., Thurlow, M. L., McGrew, K. S., \& Shriner, J. G. (1994). Recommendations for making decisions about participation of students with disabilities in statewide assessment programs (Synthesis Report 15). Minneapolis: University of Minnesota National Center on Educational Outcomes.

This research was supported in part by Grant \#H023F70010 from the U.S. Department of Education, Office of Special Education Programs, and Grant HD 15052 from the National Institute of Child Health and Human Development to Vanderbilt University. Statements do not reflect the position or policy of these agencies, and no official endorsement by them should be inferred. 